\title{
Cinematic Chaos, Catastrophe, and Unpredictable Embrace
}

In the halls of research universities and R\&D labs, specialists have been trying to make sense of the world through nonlinear simulations for seventy-five years. The transition from being a niche scientific paradigm to becoming an epistemic frame broadly held by the public has been gradual. The 1970s saw concepts like catastrophe theory and fractals gain a certain amount of public awareness, then chaos theory the following decade. In the late 1980s and early 1990s cultural theorists like N. Katherine Hayles began to reflect on what effects these ideas were having on literature and the arts, ${ }^{1}$ and postmodern theorists like Jean-Francois Lyotard named several of these discourses as a sign of the breakdown of "grand narratives" in the sciences. ${ }^{2}$ These exotic and strange forms of mathematics were the more salient side of a general shift that was seeing parts of everyday life like weather, climate, economics, and public health being understood through nonlinear simulation. When something goes wrong, we have become accustomed to looking to such models to make sense of things. In the 2006 lecture film An Inconvenient Truth, Al Gore uses climate simulations to convince viewers of the gravity of climate change, showing us what the world will look like if we do nothing. Models and projections have become accepted points of reference in the press for everything from epidemic outbreaks to market crashes. Nonlinearity has become the embodiment of unpredictable change. We increasingly see events as the product of a random stochastic factor inserted into an equation, or the complex dynamic interaction of many different factors within a system. Yet we have also

(C) The Author(s) 2021

J. Gowanlock, Animating Unpredictable Effects, Palgrave Animation, https://doi.org/10.1007/978-3-030-74227-0_6 
started to place our faith in simulation to understand, predict, and even benefit from nonlinear chaos.

Popular feature films that portray unpredictable change demonstrate this cultural epistemic shift over time. Films during successive periods since 1982 show nonlinearity increasingly becoming a way to represent an unforeseen threat. Simultaneously, simulation has emerged in these texts as a tool that offers reassurance in the face of this unpredictability. Nonlinear animations play a key role in rendering these threats and reassurances on screen by visualizing unpredictable phenomena like waves, storms, and planetary catastrophes. This span of time can be approximately broken down into three key phases. In the earliest of these periods nonlinear animation is used to create diegetic simulations that evoke a sense of totalizing computational mastery. In the late 1990s and early 2000s, it is used to convey the menace of unpredictable, catastrophic events, while diegetic scientific models offer the reassurance of prediction and understanding. Finally, and most recently, nonlinear animation is deployed in animated features to represent an at-first threatening unpredictable force that characters befriend and harness for good.

Understanding the way these nonlinear animations make meaning and the way they interact with the themes and narrative of these films requires some initial theoretical consideration. The images discussed in this chapter are unquestionably spectacular. They feature prominently in the promotional material for the films in which they appear, and the texts tend to dwell on them, giving the spectator time to marvel at their technical feats. Annette Kuhn and Andrew Darley have used the term spectacle to emphasize how divorced visual and special effects are from the narrative and themes of the films that feature them. ${ }^{3}$ Some see this spectatorial divorce as a positive quality, following Tom Gunning's suggestion that the "cinema of attractions" mode of spectatorship "goes underground ... as a component of narrative films, more evident in some genres." 4 From this perspective, effects spectacles have the capacity to be reflexive, to draw attention to themselves as media. As Dan North puts it, special effects are always about the relation between "the real and its technological mediation." ${ }^{5}$ As Chap. 3 noted, such moments of spectacular effects have often served to forefront a new filmmaking technology and position its industrial status. Moments like Al Jolson's synchronized sound performance in The Jazz Singer (1927) declare to audiences that this is the future of cinema. In these moments feature films act like a sort of SIGGRAPH 
promotional "tech demo." Effects spectacles reflect on the technologies of their making because they represent a suspension of narrative.

Consistent with this established scholarship on spectacular visual and special effects, the examples in this chapter offer moments of suspension where viewers marvel at a spectacle. These effects are legible as effects. When you watch the mountains in Star Trek II: The Wrath of Khan (1982) or the gigantic waves in The Day After Tomorrow (2004) or Frozen II (2019), you can see the effect. Indeed, you can even tell that there is a special, unusual quality to these effects. They appear too detailed and unpredictable to have been made by hand. These examples are all bold demonstrations of technological sophistication and production scale, yet to say that this is the only meaning they produce would be extremely reductive. All these examples have meaning as a part of the particular texts they are in, and the combination of narrative, theme, and spectacle has some much more nuanced things to say about nonlinearity, risk, disaster, and simulation.

While spectacles are occasions to presentationally forefront effects, this does not preclude them from connecting to the themes and narrative of the rest of the film. Lisa Purse argues that thinking dichotomously about digital spectacle and narrative "fails to capture the complex manner in which digital literacy of various kinds might intersect with narrative meaning."7 Aylish Wood finds that these suspended moments of spectacle expand the time and space of the narrative rather than interrupting it. ${ }^{8}$ Following Bob Rehak's theory of the special effects "micro-genre," Kristen Whissel argues that different types of effects produce different types of meaning within texts as "allegorical assemblages" or "spectacular elaboration(s) of concepts." To use Rehak's example, the "bullet time" effect made famous by The Matrix (1999) has a particular narrative and thematic function within film texts. ${ }^{10}$ Nonlinear animations can be interpreted as one such micro-genre, and they interact with the themes and narrative of the films in which they appear in important ways.

The nonlinear animation spectacles profiled in this chapter use nonlinearity to dramatize the threat of the unpredictable and unknown. Economic crashes, natural disasters, organizational collapse, and climate change are all represented through nonlinearity in these films as a way of communicating their unpredictability, non-anthropocentrism, and meaninglessness. At times they conjure a sort of Old Testament rendering of catastrophic change, presenting us, like the biblical Job, with adversity we cannot comprehend. Yet nonlinear simulations also frequently posed as a 
way to model the unpredictable and give meaning to the meaningless. Diegetic computer models explain the mechanisms behind the disaster, and often a scientist predicts it, only to have their predictions fall on deaf ears. In the most recent examples, unpredictable chaos becomes something to embrace and benefit from. These uses of nonlinear animation are a continuance of cinema's long history with contingency. Mary Ann Doane observes that cinema codes contingency into a "representational system while maintaining both its threat and its allure." 11 Nonlinear animation is deployed in these films in a similar way, both to representing a threat and to managing and making sense of that threat, even to convey as a sense of empowerment against the threat.

This theme of empowerment is something Lisa Purse and Scott Bukatman have already recognized at work in spectacular special effects. Bukatman describes the spectatorial pleasure of, "conceptual mastery over the complex," 12 and Purse writes about how digital special effects sequences, "can dramatize power relations forcefully, articulating fantasies of empowerment in which the mastery of the visible offered by the sequence metaphorically correlates to the physical mastery or dramatic disempowerment of the protagonist." ${ }^{13}$ Both of these examples emphasize embodiment in relation to this experience of empowerment or disempowerment, but the following examples will be less focused on the representation of bodies and more on the representation of software users as the empowered.

The following sections cover three key eras in nonlinear discourse and examine the way they appear in narratives, themes, and visual effects aesthetics on screen. Each era demonstrates how society was beginning to understand the world through nonlinear paradigms and how it was seeking to develop tools to master unpredictable change. The first covers chaos theory and fractals as a way of modeling ecological change, the second covers terms like "perfect storm" and "catastrophe" as systemic and nonlinear ways of styling the ontology of disasters, and the final section covers the flexible and responsive approaches to management discussed in Chap. 5 that seek to capitalize on the creative power of unpredictability. The films in these three eras all thematically reflect on the ontology of emergence: where things like catastrophes, disasters, and even life itself come from. They also use VFX to render a spectacular visual equivalence of this emergence. When combined, they create moments of sublime marvel and horror. Yet these are also all stories of mastery, of contingency predicted and quantified, and of randomness given meaning. 


\section{Fractals and ChaOs}

When nonlinear animation first appeared in feature films it was steeped in a visual and narrative discourse of the creation of unpredictable artificial life. Concepts like chaos theory and fractals had gone from being the subject of arcane mathematics in the 1970s to being part of popular culture in the 1980s. The homology between the shapes produced by these new equations and shapes in nature proved to be fertile ground for wild speculation about computer simulation's ability to replicate natural processes. Between the 1980s and early 90s, films prompted spectators to marvel at the uncannily naturalistic appearances of these forms, but they also raised the specter of the threat of chaotic artificial life.

The first example of nonlinear animation in a feature film, the "genesis sequence" in Star Trek II: The Wrath of Khan, offers a clear example of early nonlinear discourses. In the fictional world of the film, the genesis project is a technology that can create life. The software used to animate it was itself based on fractal and stochastic mathematics. The film thus collapses the difference between simulated emergence and real emergence, and the difference between narrative theme and VFX spectacle. The genesis sequence was the product of one of the many early crossovers between military-industrial complex research and the film industry at SIGGRAPH. In 1980 Loren Carpenter, an engineer at Boeing's Computer Service Department, presented a short animation titled Vol Libre, which showed off his technique for drawing realistic looking geological topographies using a combination of fractals and stochastic computational processes. By inputting a few parameters, Carpenter could automatically generate a realistic landscape of mountains and valleys. When Carpenter showed Vol Libre in at the end of his 1980 SIGGRAPH presentations, the crowd allegedly erupted in applause and demanded a second viewing. After his talk, he was immediately offered a job by Alvy Ray Smith and Ed Catmull at the Computer Division of Lucas Film. ${ }^{14}$ Lucas Film would put Carpenter's technique to use almost immediately on The Wrath of Khan's genesis sequence. Carpenter would soon go on to design other nonlinear technologies, like the L-system technique used to generate realistic foliage in The Adventures of Andre and Wally B (1986). Much like Carpenter's topographical fractals, L-Systems simulate natural patters. First discovered by a botanist, they are algorithms that imitate different bifurcation patterns of plant branches. Both technologies traded on the idea of computer graphics having computational realism that could produce visual realism. 
In The Wrath of Khan Captain Kirk's (William Shatner) United Federation of Planets has developed a technology called the "genesis device," which can terraform barren planets and cover them with plant life. This seemingly benign technology is stolen by the genetically modified super-villain Khan Noonien Singh (Ricardo Montalban), who intends to use it as a weapon. The sequence Carpenter made for the film is an explanatory interlude where the genesis device's function is demonstrated using computer graphics. The entire sequence takes place on a diegetic computer console screen, with Kirk, Dr. McCoy (DeForest Kelley) and Mr. Spock (Leonard Nimoy) gathered around the screen, viewing the demonstration. As a classified military demonstration, the sequence serves a similar diegetic function to the computer graphics technologies that preceded it at Boeing and SIGGRAPH. The narrating scientist even refers to the fact that this project's research would require further funding from the Federation of Planets. One could imagine such a film being made by Boeing to inform a military general about some new aerospace technology. The diegetic simulation and the nonlinear animation it is made of are remarkably close.

In the computer graphics sequence the camera starts at space scale, viewing an entire dead planet in a field of darkness. The camera then begins its ballistic journey forward, zooming down to the surface of the planet. While the camera pans to the left to see the surface of the planet, it continues to hurdle forward through space. The entire sequence is one continuous shot, save for a cut back to the crew viewing the sequence to show their reaction. This aesthetic combination of extreme camera movement and long take is a standard of computer graphics tech demos of the time, because is aggrandizes the ability of computer graphics to render complete three-dimensional (3D) space. ${ }^{15}$ Before computer graphics, moving the camera in animation required laborious processes like Disney's multiplane camera or John Dykstra's motion control camera. This shot would have been impossible with the multiplane camera because the camera pans while moving forward at the same time. As Thomas Lamarre notes, Disney's use of the multiplane camera only allowed for a "bullet's eye view" looking straight ahead as it moved through transparent layers. Here any type of movement seems possible. Thus, the camera movement in this sequence functions as a demonstration of what digital animation can do, and Carpenter's stochastic shapes serve a similar function.

As a warhead hits the dead planet an explosion takes place on the surface, causing a catalytic reaction, and a fiery red shockwave, animated 
using William Reeves' particle systems, encircles the planet. The flat planetary surface then begins to grow new topography with mountains ranges and valleys. Troughs fill with water and exposed surfaces grow green with vegetation, using Carpenter's fractal drawing technique. As with Vol Libre, the shape of these features is legibly computational in nature. The lines of the peaks and valleys look too unpredictable and infinitely detailed to have been done by a human hand. They exude naturalistic computational origins. They both illustrate the film's theme of artificial creation while functioning as a sort of tech demo for nonlinear animation.

Like the other digital VFX milestone from the same year, Tron (1982), The Wrath of Khan contains digital effects within the frame of a diegetic computer rather than attempting photorealism. The images are presented as a computer simulation of what would happen if the device were used. The genesis sequence visualization is thus a diegetic futuristic simulation made using an actual futuristic simulation. In many of the following examples in this chapter there will be diegetic digital screens displaying data and simulations. In those cases, though, the VFX spectacle lays somewhere else in the film as a photorealistic image. Here, the diegetic simulation and the nonlinear animation coincide. While critical discussion of digital effects over the last few decades has been dominated by the discourse of synthetic photorealism, there is a different sort of realism at work here: the realism of computational mediation and nonlinear simulation.

Beyond the mere presence of a simulation, the film taps into several concepts from the science of nonlinear systems and simulation, which were becoming familiar to the public at the time. One important concept is fractals. ${ }^{16} \mathrm{~A}$ fractal is an algorithm that generates infinite nested selfsimilar patterns. In the 1970s mathematician Benoit Mandelbrot argued that these algorithms had the potential to describe shapes and processes in nature. ${ }^{17}$ For example, in a paper for the journal Science he argues that the British coastline is a fractal patter because the closer you study it the more complex and detailed its shape becomes. ${ }^{18}$ Fractals had a level of popularity in the 1980s and 90s that far outpaced their utility. They exceeded computer science and mathematics circles to become a part of popular culture. The visually compelling way fractals rendered nonlinear complexity made them extremely popular: fodder for dorm room posters and blockbuster movies. This trend started with Heinz-Otto Peitgen and Peter Richter's book The Beauty of Fractals (1986). Although the book was fairly technical, it featured large full color prints that anyone could appreciate. ${ }^{19}$ Three years later, the New Museum in New York featured an 
exhibit titled "Strange Attractors" (1989) which featured fractal renderings of chaotic phenomena. ${ }^{20}$ Fractals soon became a household name.

The animation in the genesis effect sequence is a modified fractal. Carpenter's contribution was to add stochastic elements and map the fractals into 3D surfaces in a way that seemed to mimic the unpredictable processes that formed the earth's surface. As the narration in a Lucasfilm making-of video titled Computer Graphics in Star Trek II: The Wrath of Khan describes it, "the fractal technique is a form of controlled randomness which ads a nature-like dynamic complexity to simulated scenes." 21 The way one can grow the crystalline structure of a fractal, and the way that structure can convincingly mimic patterns in nature, tempts the assumption that computation is not simply a theory that models reality, but rather that it is reality in some respect.

Although the making-of video is careful to describe Carpenter's animation as "nature-like," the film collapses the difference between simulation and natural process. Another example of this discourse from the same period is John Conway's Game of Life, noted in Chap. 2. Based on John von Neumann's concept of cellular automata, Game of Life uses a grid of squares with specific rules for being on or off to produce emergent, evolving patterns, where squares seem to coalesce and form functioning entities. Enthusiasts developed a taxonomy of different life forms that emerged from Game of Life simulations with names like "glider guns." 22 Much like fractals, Game of Life was a popular program to play with on expensive institutional computer systems. Conway's program shows how fundamental nonlinearity is to this discourse because it is emergent in nature. Just like any form of nonlinear animation, the user simply sets initial conditions and parameters, and the software animates the field of squares with vital complexity.

This discourse is very much a product of the Cold War R\&D context that cultivated nonlinear simulation. As scholars like Philip Mirowski, ${ }^{23}$ Catherine Hayles, ${ }^{24}$ and Warren Sack argue, ${ }^{25}$ computer scientists have had a tendency to ignore the difference between a simulated process and a real-world process, assuming that the real world in fact conforms to the logic and characteristics of the computational machines we have built to imitate it. Philip Mirowski calls this discourse "cyborg science" and Warren Sack calls it "computational thinking." Hayles shows how nonlinear simulation in particular plays a part in this discourse using examples like mathematician Steven Wolfram's controversial book A New Kind of Science. Wolfram believes the mechanism behind unpredictable processes in the 
world, like the patterns of leopards' spots, are driven by the exact same mechanism as simulations. They are not a model of the process but the process itself.

The genesis sequence in The Wrath of Khan taps-in to these discourses of cyborg science or computational thinking at work in fractals, L-systems, and Conway's Game of Life. The diegetic concept of a tool that could create life on a dead planet overlaps perfectly with these ideas. The sum effect of the sequence is that we are witnessing real digital life on screen. The fact that the genesis device is represented through a diegetic simulation strengthens this connection. As Kristen Whissel theorizes, the narrative and the spectacle are conspiring to emblematically convey a concept. They make this discourse of emergent virtual life sensible in a unique way that narrative, aesthetics, or VFX spectacle on their own could not. They also collapse the difference between simulation and reality, embracing the concept that a simulation could give rise to natural life patterns, and that patterns like the shape of mountains and the spacing of branches on trees follow the rules of computation, rather than the other way around. From this perspective the naturalism, even the realism, of simulated digital images becomes unassailable.

The narrative of The Wrath of Khan follows the members of the starship Enterprise trying to stop Khan from using the genesis device as a weapon. The film thus points toward a potential fear of this creative power. This trope of human endeavor going too far and being humbled by nature recalls Goethe or Shelley, yet the film does not belabor this perspective. The effect of the genesis sequence is one of technological mastery, above all else. Other films toward the end of this era begin to emphasize the threat of nonlinearity much more.

The concept of emergent virtual life is still at work almost a decade later in another VFX landmark film, perhaps the single most iconic digital VFX film. Jurassic Park (1993) is unique among the examples in this chapter because, despite the film being a VFX landmark, it does not feature any significant form of nonlinear animation. Though as Warren Buckland notes, the realistic looking synthetic dinosaurs convey the impression that they are simulated life. ${ }^{26}$ The film is further preoccupied with nonlinear simulation concepts and still manages to make a connection between these themes and its VFX spectacles. Thus, it merits brief mention. Jurassic Park belabors the connection between the computer code of digital objects and the code of DNA, and through this a sense of mastery not unlike that of The Wrath of Khan. Here scientists can synthetize life and sculpt it, and 
the process is explained using diegetic computer graphic visualizations much like the genesis sequence. The film's other thematic interest, though, is the nonlinear mathematics of chaos theory. The emergent life of the dinosaurs, and the disaster that ensues, are thus mediated through the concept of nonlinear simulation. Although the film ends with unruly life run continuing to run amok, the film has proven to be a popular metaphor for systems management literature. At least three academic articles on management use the film to discuss the management of nonlinear systems. ${ }^{27}$

In the film, a doubting chaos mathematician named Dr. Malcolm (Jeff Goldblum) anticipates that the park will inevitably descend into entropy and disorder, and eventually it does. Edward Norton Lorenz first developed chaos theory when he was working on early dynamic simulations of weather patterns. Lorenz discovered that any minuscule input into his simulations resulted in wildly different outputs. If he changed one tiny thing in a complex system, everything would be affected. This was a product of the complexity produced by a dynamic simulation. Lorenz also eventually discovered that certain mysterious patterns emerge in wildly complex and unpredictable systems. It was highly counter-intuitive to find regular patterns in what should have been unpredictably complex systems. He referred to the mysterious causes of these patterns as "strange attractors." Chaos theory thus concerns the mysterious forms of order in what should be order-less systems. The film focuses more on the unpredictable aspects of chaos rather than the subject of strange patters. Chaos theorist Dr. Malcolm seems to believe that no complex system can be controlled. Thus, what is most significant about the film's use of chaos theory is the term's popular meaning. The Pulitzer Prize nominated 1987 book Chaos: Making a New Science brought these strange yet compelling mathematical ideas to the lay public. ${ }^{28}$ The popularity of chaos theory was also helped by its connection to fractals, which offer a spectacular way to visualize chaotic systems. Indeed, the New Museum 1989 exhibit on fractals "Strange Attractors" was as much about chaos theory as it was about fractals.

Jurassic Park points to a trend that becomes more dominant through the later 1990s and 2000s where nonlinear animation is increasingly used to dramatize the threat of the unforeseen and unpredictable. Therefore, it is a liminal case between The Wrath of Khan and later films, as it is both preoccupied with the topic of artificial nonlinear life and with the threat of nonlinearity. 


\section{Perfect Storms, Catastrophe, and Climate Models}

While films in the 1980s and early 1990s were preoccupied with the hidden mainspring of life itself, over time popular interest started to center on things in the world that are more relatable as nonlinear. Some things in our world, like the changing of the seasons or ocean tides, are reliably predictable, but there are many other unpredictable things in the world that we must constantly contend with. Countless people in financial industries try in vain to anticipate the unpredictable movement of stock markets. Farmers and mariners have had to contend with unpredictable weather patterns since prehistory. This era focuses in on the ontology of these unpredictable phenomena that affect our lives: where they come from, what they are, and whether we can understand them.

The 1996 film Twister centers on meteorological researchers who are trying to develop a technique for predicting when and where a tornado will touch down. The question they are trying to answer is thus how events precipitate from within complex dynamic systems. Weather prediction has been one of the key applications of nonlinear animation. It is one of the great successes of the technology. While the narrative of Twister does indeed tell a story of the triumph of simulation and its ability to predict the seemingly unpredictable, the film uses nonlinear animation in VFX sequences to conjure a sense of threatening unpredictability to bring the monstrous tornado to life.

The scientists in Twister are trying to study tornadoes by filling them with thousands of motion-trackers to understand their behavior and make them more predictable. To do this they must, of course, chase storms, and they are constantly imperiled by the unpredictability of these weather phenomena in dramatic and spectacular fashion. The unpredictability of the storms is key to their menace in the film. They can appear out of nowhere in a seemingly calm situation, and they are often obscured by darkness or trees. One of the tornado-chasing scientists (Helen Hunt) reflects on the horror of the unpredictability of tornadoes, she describes how they "skip this house and that house and come after you." The tornadoes represent, to use Mary Ann Doane's words, "unalloyed contingency," an untamed form of risk that has not yet been given meaning through mediation or scientific study. ${ }^{29}$ The film's approach to the unpredictable emergence of tornadoes recalls a popular discourse from the field of nonlinear mathematics: catastrophe theory. 
Like chaos theory and fractals, catastrophe theory is a nonlinear mathematical theory that grew to have cultural meaning. Rene Thom coined the term to describe the moment a system goes from a state of "smooth change" to a state of "abrupt response." ${ }^{30}$ In other words, he investigated what happens at the moment when a predictable situation "bifurcates" into unpredictable dynamic change. British mathematician Erik Christopher Zeeman developed Thom's initial ideas further in the 1970s and applied them to topics as diverse as brain modeling, the stock exchange, biology, and the stability of ships. Zeeman's work led to a greater popularization of the concept, likely because he also developed a compelling visual model for his ideas, the catastrophe machine. The catastrophe machine consists of a rubber band fixed at one point, then connected at its midpoint to the edge of a pivoting disk. As you move the unfixed end of the rubber band around, some positions will cause the disk to rotate smoothly, while other cause the disk to rapidly spin back and forth. Charting these positions allows you to visualize the threshold where smooth change tips over into abrupt change. This model offers a compelling illustration of the way a regular, predictable state of affairs turns into an unpredictable situation.

In the film the opaque, seemingly meaningless way storms behave feeds a sense of fear. In this sense, the concept of nonlinearity is not used to tame or rationalize the unpredictable process, but to animate it. Industrial Light and Magic animated the complex, detailed swirling of particles in the tornado with Wavefront's recently released software Dynamation. ${ }^{31}$ The animation of the tornado is legibly complex and unpredictable, and that sense of nonlinearity illustrates and animates the film's themes. The animated tornado is an emblem for these ideas. It conveys a sense of simulated catastrophic unpredictability.

The threat of raw contingency is eventually overcome in the film when the scientists gather enough data to make a predictive model. The model will finally provide some answer to the menacing unpredictability of the tornado. The resolution of the narrative sees the scientists succeeding in inserting dozens of motion trackers into a tornado. As the motion trackers are sucked up into the tornado, the scientists look at a computer visualization of their motion paths. This visualization thus represents a different face of nonlinear simulation, one that can tame contingency and give it numerical meaning. With this information they can create models of the phenomenon and learn to predict it. Thus, simulations ultimately provide an opportunity to control the unknown. 
Weather is in many ways the archetypal nonlinear system. As I noted, Lorenz's discoveries about chaos came from weather simulations. Weather modeling and prediction have been major drivers of research in nonlinear simulation in institutions like the Los Alamos National Research Laboratory. Weather is also a familiar and relatable kind of contingency. Humans have always been at the mercy of the unpredictable nature of changes in weather. These combined factors make it a prime subject for the epistemology of nonlinear simulations.

Like Twister, The Perfect Storm (2000) is a blockbuster movie about the weather and the nature of contingency, and it animates unpredictable weather events using nonlinear animation. This film takes a slightly different approach to understanding emergence though, focusing on the complex conditions that precipitate unlikely events. It also makes reference to economic risk in relation to the weather. The film is based on the real-life fishing crew of the Andrea Gale, which was lost during a historical weather event that took place in the fall of 1991 in the North Atlantic. This weather event has been referred to as the "Halloween Nor'Easter," "The No-Name Storm," or "The Perfect Storm." In the film the crew has an unusually good haul of fish far out in the Atlantic, but amidst their economic success their icemaker breaks down and they are forced to choose between letting their catch spoil or attempting to sail through a storm to get to port. As they enter the storm conditions worsen and the ship is lost with its crew. The story is thus not just about unforeseen events but also about economic risk in relation to those events.

As the crew are in the midst of a worsening storm, the film cuts to a meteorologist (Christopher McDonald) looking at a visualization of a computer model. He explains to a co-worker how pressure systems and air masses are interacting with the already-formed Hurricane Grace to create a super-storm. The visualization shows past radar maps, as well as simulations of the near future. As he points to a computer screen, he says, "you could be a meteorologist all your life and never see something like this; it would be a disaster of epic proportion..." Every one of these unlikely factors had to be in place at the exact right time for a storm of this magnitude to take shape. This is the definition of a perfect storm, a term that the film (and the book it was based on) popularized. ${ }^{32}$ This scene creates dramatic irony, as the crew are unaware of these developments, even though meteorological computer models were able to predict them. The crew knew they were taking a risk, but they did not know the odds. 
This situation recalls Louis Bachelier's original theory of using stochastics to calculate economic risk in Chap. 2, a concept that Fischer Black and Myron Scholes developed into their eponymous model, which transformed finance in the 1970s, allowing formerly unknown risks to be calculated. These methods obviously cannot predict the future; rather they allow investors to know the range of possible values something might have, even if unpredictable events occur. The little bit of randomness in these equations thus stands-in for the unknown. And in the film this unknown factor is visually represented by a colossal rogue wave, animated using nonlinear animation. The effects in this film represented a significant advance in fluid simulation. The bulk of the film takes place at sea in the storm, and while the actors and the boat set were shot in a water tank, the ever-present ocean setting was entirely animated through ILM's OCEAN fluid simulation technology. It is perhaps the best example of the second generation of fluid simulation described in Chap. 3 .

The term perfect storm has taken on even more specific meaning in the decade following the film's release, as it was used frequently in press stories regarding to the global financial crisis of $2008 .^{33}$ Financial markets are akin to weather in that they are highly unpredictable dynamic systems that certain groups would benefit immensely from understanding better. Like weather disasters, economic disasters are a form of contingency that is important to the average person. The average worker with retirement savings is not unlike the farmer of past centuries, both must contend with the knowledge that their prosperity relies on changes that are beyond their ability to predict. The generalization of this term as a part of common speech suggests that we have begun to think of all sorts of phenomena in terms of nonlinear systemic change.

The film's focus on the conditions that precipitate unlikely events recalls the National Centre for Supercomputing's 1989 Visualization of a Numerically Modeled Severe Storm. This computer visualization, which used an early version of Wavefront software, was so visually compelling it was nominated for an Academy Award. ${ }^{34}$ The visualization was based on a National Centre for Supercomputing simulation of a devastating weather system in Oklahoma in $1964 .{ }^{35}$ Scientists took atmospheric conditions from that event and tried to see if they could precipitate similar events in a dynamic simulation. Thus, the simulation they produced was not a model of the actual storm, but a model of a storm that was produced by the same conditions. This is a nuanced ontological distinction, and one that demonstrates nonlinear simulation's complex relationship to time and 
contingency. The Perfect Storm endeavors to represent and animate the past in this way. Cleary it does not carry the evidentiary weight of a government supercomputer simulation, but the film's spectacular nonlinear waves evoke a sense of past events emerging from historical conditions.

The Perfect Storm thus has several references to risk mediated through nonlinear simulation held in tension with each other. Much like Twister, the diegetic use of simulations seems to suggest science's ability to make sense of unforeseen catastrophe. The storm is explicable after the fact, and indeed even right before, as a confluence of factors. Had the crew of the Andrea Gail known what meteorologist knew, they could have made a more informed bet, like a contemporary investor. Yet there is also an enduring threat here, that random figure in the equation, illustrated in the form of the simulated waves, a form of uncertainty that is no less menacing for its simulation. It is not as though mariners or investors live their lives in untroubled security thanks to simulation. Even the quantifiable can be terrifying.

Nonlinear images of storms and waves during this period have an aesthetic presence that could only be described as sublime. They are partially obscured by darkness, lit in deep chiaroscuro, allowing only brief glimpses of their totality when lit by lightning strikes. They dwarf all anthropogenic structures around them and swallow characters. The motion of their edges and within their bodies of swirling eddies and vortexes conveys a sense of overwhelming complexity. These moments of visual effects spectacle humble attempts to quantify the storm or predict its behavior. Yet, importantly, it is not the power of nature that is meant to inspire terror, but the power of a nonlinear system. What is more terrifying to the average American than financial catastrophe, after all?

Writing about special and visual effects during this period of time, Sean Cubitt finds these images to be sublime, yet he interprets this effect as one that divorces them from both the meaning of the narrative and reality in general, in a typical postmodern fashion. He describes them as "extra temporal" and "extra historical," yet the threat and pleasure these films deliver is very much a product of their time and it is vital to their narrative. ${ }^{36}$ Scott Bukatman finds that sublime images in special effects are historical in the sense that they convey the "loss of cognitive power experienced by the subject in an increasingly technologized world." ${ }^{37}$ That sense of the loss of power is conveyed in these films through overwhelming complexity. And as Bukatman further argues, special effects can deliver the pleasure of mastery in response to this threat. ${ }^{38}$ This is clear in the conclusion of Twister, 
where the symbolic defeat of the monstrous storms comes in the form of a successful computer model. This is also clear in another example from this era, The Day After Tomorrow.

Released just four years after The Perfect Storm, The Day After Tomorrow takes a similar approach to weather catastrophes, but with the added dimension that it is oriented toward imagining possible futures rather than representing the past. The epistemology of nonlinear simulation lends itself to this sort of temporal flexibly. Just as simulations of past events speculate about how phenomena can emerge from specific conditions, simulations of the future can speculate about how current conditions might give rise to events that have not yet happened. This ability to predict the future is a key factor driving research into simulation tools.

Along with An Inconvenient Truth, The Day After Tomorrow is one of the two key films of the 2000s that sought to promote awareness of anthropogenic global climate change to the public. ${ }^{39}$ The title of the film is meant to evoke the widely watched 1983 telefilm The Day After, which portrayed a hypothetical global nuclear war and its aftermath. The implication being that climate change is the present generation's version of the global peril of nuclear war. ${ }^{40}$ Like The Perfect Storm, The Day After Tomorrow is notable for its use of new fluid simulation tools. Promotional material, especially trailers, heavily featured clips from a sequence where a colossal wave crashes into New York City, engulfing the statue of liberty and carrying freight ships downtown, crashing into buildings. This wave was animated using Digital Domain's FSIM dynamic simulation software. This effect belongs to the same second-generation technology of fluid simulation techniques as The Perfect Storm. ${ }^{41}$

The Day After Tomorrow imagines a future where anthropogenic changes in global temperatures set off dramatic changes in weather. The weather phenomena portrayed in film are, however, so dramatic, so rapid and on such a great scale, they detract from verisimilitude. They are frankly ridiculous. Events featured in the film include the aforementioned wave in New York, which is as high as a skyscraper, a series of tornadoes that tear apart buildings in downtown Los Angeles, and the sudden onset of a new ice age that renders most of the United States uninhabitable. All these events occur in the matter of a few days. The film follows in the many disaster genre tropes of its time, established by films like Independence Day (1996) and Armageddon (1998), where a great deal of visual novelty (and perhaps perverse pleasure) is derived from seeing recognizable landmarks and locations catastrophically destroyed. ${ }^{42}$ The Day After Tomorrow is 
however noteworthy for the way it poses thematic tropes, conceptual frames, and visual spectacles relating to nonlinear dynamic systems and simulation.

Much like Twister and The Perfect Storm, The Day After Tomorrow features sequences where a scientist explains the causes that lead to these catastrophic events. Indeed, they all feature a strikingly similar scene where a scientist looks at a computer model and predicts the impending disaster, only when it is already too late, of course. The Day After Tomorrow additionally features a scene where the protagonist scientist Jack Hall (Dennis Quaid) uses visualizations of his climate simulations displayed on a large video wall to warn a group of world leaders about climate change. He explains that changes in global temperatures could upset the regular flow of air and ocean currents, causing the system to collapse into unpredictable chaos.

The explanation the film offers of the mechanisms driving the wildly destructive events it features is more detailed in its engagement with nonlinear concepts than the other examples in this chapter. Jack Hall's description of how global air and ocean currents could be destabilized by a change in temperature is, at its core, based on the same principles as real climate change science. The global flow of sea and air currents and their exchange of heat is a complex yet stable system. In the phraseology of Rene Thom, it is "smooth." The introduction of anthropogenic warming threatens to throw this stability into disarray. Just as Lorenz found that small change in input can result in massively different results, such an abrupt change could destabilize the whole system: jet streams would move, dry areas would become wet, warm areas would become hot, and storms would become more intense and frequent. This is one of the key anticipated adverse effects of climate change. ${ }^{43}$

The feature effect in The Day After Tomorrow is a giant nonlinear animated wave. In the film the menacing, darkly lit wave engulfs the Statue of Liberty and lays waste to New York City amidst a thunderstorm. The wreckage of human endeavor in the film is reminiscing of romantic sublime landscapes of J.M.W Turner's Snow Storm: Hannibal and his Army Crossing the Alps or Philip James De Loutherbourg's An Avalanche in the Alps, where imposing, dark, highly detailed clouds descend on tiny human figures. Like the romantic sublime, this film inspires humility in the face of a natural world beyond our control. Yet ultimately it also offers reassurances in the face of this looming menace. Although Jack Hall's ability to model climate change ultimately does not save the United States from 
disaster, the message of the film is one of the power of models and of the importance of using them, part of the highly didactic aims of this climate change film.

What does a climate model tell us exactly? What kind of evidence does it provide us? This is a scientific question, but it is also a question the lay public needed to negotiate. Understanding climate change requires accepting evidence from data models and simulation. Although it may seem that simple data points such as historical ocean temperature recordings are the primary source of our understanding of climate change, these data points are meaningless until climate researchers put them into a model. As Paul Edwards argues, "everything we know about the world's climate - past present, and future- we know through models." ${ }^{44}$ The film seems to be taking on a public education role, informing still-skeptical citizens of the evidentiary value of simulations.

The Day After Tomorrow uses simulation to represent possible future events, rather than events in the past. It is representing something more abstract than The Perfect Storm's Halloween Nor'Easter storm. Digital media and games scholar Mark Wolf has proposed a new way of thinking about truth claims through simulation, which he refers to as "subjunctive documentary." He argues that simulations are not limited to representing what is or was, rather they can also represent "what could be, would be or might have been." 45 Wolf's subjunctive documentary fits halfway inbetween fiction and documentary, it is imaginative, but it is also oriented toward understanding reality. Citing Jonathan Crary's Foucauldian study of optical tools, Wolf suggests that in the same way we began to understand reality through the new visibilities created by microscopes and telescopes, our understanding of reality is changing once again through the episteme of simulation. The laws of physics used in computer simulations are simply new "conceptual indices" to reality. ${ }^{46}$ Clearly Wolf is not thinking about the ludicrous VFX in The Day After Tomorrow here, but his ideas gesture toward the epistemic possibilities of thinking through nonlinear simulation. If simulation can create a different kind of documentary, then it must also be able to create a different kind of fiction. The Day After Tomorrow takes present conditions and imagines the resulting storm, animating the storm with nonlinear animation. So, while the film offers an image of disaster, it offers a sort of moralistic fable about a possible future if we ignore the models, as the people in the film do. As the public began to see threats through a nonlinear paradigm, simulation offered an antidote. 


\section{UnPredictable Embrace: Resilience and Creative Management}

The popular discourses concerning nonlinear simulation in the late 1990s and early 2000 s that saw unpredictable nonlinearity as a threat that needed to be managed gave way to a much more positive outlook in the following years. Increasingly, chaos has become something to be embraced and directed toward productive ends. This third and final era is best represented by animated features. As Chap. 5 noted, nonlinear simulation was a key component in a shift in the history of management that facilitated greater organization resilience. Pixar promotes their own brand of this school of post-Taylorist management that focuses on embracing unpredictably through flexibility. Their brand of animated management is influenced by the company founder's experience developing nonlinear animation tools. As co-founder and former head of Pixar Ed Catmull writes in his book on the subject, "to my mind randomness is not just inevitable; it is part of the beauty of life ... The unpredictable is the ground on which creativity occurs." 47

Given that this approach to nonlinearity was fostered at an animation studio, it should come as no surprise that animated features have begun to exhibit this way of thinking. Unlike the VFX disaster spectacles of the late 1990s and early 2000s, or early examples like The Wrath of Khan, these examples do not bridge the gap between nonlinear themes and their animated equivalents through diegetic frames of predictive computer models. Instead, animated characters that are imbued with an unpredictable and difficult-to-divine will of their own embody themes relating to nonlinearity in these films. These characters are, of course, animated with nonlinear animation.

In Disney's Moana (2016), a mysterious ecological disaster threatens the eponymous pacific island princess's community. Unlike the rest of her village, Moana shares a special kinship with the sea. In a flashback to her childhood, we see her as she toddles close to the waves and a figure takes shape on the surface of the turquoise water, resembling the alien pseudopod from James Cameron's The Abyss (1989). Though the waves ripple and splash with naturalistic unpredictability, the pseudopod bends and gesticulates with the intentionality of an animated character and exhibits as sort of nurturing care for the young Moana. This scene sets up her connection to the ocean and her journey into its unknown expanse to save the village. The people of Moana's village are fearful of traveling into open 
water, and the narrative arc follows her journey past their islands protective reef. In a key scene she tries to pass the shoreline waves in an outrigger canoe, breathlessly falling beneath the waves before being washed back to shore. The ocean is therefore an ambivalent combination of threat and friend. Over her journey there are several such set pieces involving the ocean. The film's production included substantial R\&D for the development of a new fluid simulation pipeline, including a new solver that Disney Animation dubbed "Splash," which led to at least four SIGGRAPH papers. The fluid FX in this film was thus an important component of both its production and a promotional demonstration of Disney Animation's technical capabilities.

In the conclusion of the film, Moana averts the impending ecological disaster threating her people and they return to exploring the seas as their ancestors did. Thus, while the villagers start out fearing the unpredictable power of the oceans, when Moana endeavors beyond the safety of the reef she eventually discovers a harmony with the ocean that leads the village to prosper, with her as their leader. Ed Catmull writes in Harvard Business Review that embracing risk can be "downright scary," but he encourages other CEOs to follows his example and build structures that embrace unpredictability. ${ }^{48}$ While this philosophy of nonlinear animated management has had wide-reaching influence, perhaps no company has been more influence by it than Disney Animation. After Disney purchased Pixar, Catmull became head of Disney Animation. The very fluid animation pipeline the film features is a product of this same philosophy. R\&D is a risky venture. It takes time and money, and the return outcome is rarely certain. Yet Pixar has made R\&D a key component of their operations, and when Disney purchased the studio, they founded their own dedicated R\&D wing, Disney Research. Although Moana's fluid pipeline and Splash solver were not the product of Disney Research but rather part of the production budget for the film, they are still a product of this same risk-embracing philosophy. The theme of taking risks, embracing unpredictability, and prospering as a result in the film thus acts in unison with the technical showmanship of the animated ocean in a way that seems to declare Disney animation's adherence to Pixar's corporate philosophy.

The 2019 sequel to Disney's blockbuster hit Frozen bares strikingly similar themes and an equally similar scene to Moana. Like Moana, Elsa is a monarch attempting to uncover her familial connection to elementary forces and save her community from impending disaster. In her quest for answers Elsa crosses a threatening sea, venturing into the unknown, and 
like Moana, fails at her first attempt, nearly drowning. The rendering of the ocean in Frozen II is decidedly more threatening than Moana though, with dramatic chiaroscuro lighting, a darkened sky, and more menacing, violent waves. Indeed, the ocean is highly reminiscent of the one in The Perfect Storm. Elsa looks especially fragile struggling to keep from drowning. Although the ocean in Moana is equally as naturalistic, the turquoise color and sunshine make it less threatening, and the quality of the fluid simulation is somehow less severe, more rounded.

As Elsa struggles through the water, she is waylaid by a water horse spirit named Nøkk who fights her and attempts to drown her by dragging her deep beneath the waves. She eventually lassoes Nøkk though, making it her companion and using it to make the rest of her journey far easier. ${ }^{49}$ The ocean in Frozen II thus turns from initial menace into eventual ally. Elsa's new companion is an emblem of the benefits of embracing nonlinear chance and venturing into the "downright scary" unknown.

Clearly neither of these films has a scene with visualization on a computer screen. Yet, like the films before them, they create a thematic connection between nonlinear animation and a discourse of nonlinearity. Instead of diegetic simulations they use voiceless, spirituous characters connected to elemental powers to embody nonlinear themes. These character both initially appear as a menacing force, making nature seem just as implacable and menacing as in Twister. But while the mystery of the nonlinear becomes mastered through models in films form Twister's era, here it is befriended. It is an almost literal interpretation of Ed Catmull's philosophy that encourages people to befriend the unpredictable unknown rather than to resist it and avoid it. While this is a way of thinking about nonlinear change that has been spread to innumerable businesses, entrepreneurs, and workers through Catmull's book and his publications in Harvard Business Review, it also has specific meaning in this context. These characters are a declaration of principles for the Catmull-run Disney Animation Studio.

Both Moana and Elsa represent a new regime of management that embraces unpredictable change. It is interesting to note they also represent gendered change within their respective texts. Both replace monarch fathers, and both represent a significant shift away from the passive Disney princesses of the past that were defined through their relationship to men. Their embrace of the unknown and of the resilient management style it entails is, at least in these films, being coded not just as progressive but also as feminine. 
Between 1982 and 2019 themes relating to unforeseen and often disastrous events began to increasingly be mediated through nonlinear concepts in feature films. At the same time, nonlinear animation began to be a more common feature in both VFX and animation. While nonlinear animation does not always represent nonlinear themes like changes in weather, climate, ecology, or economics, in certain texts at key points in time it acts as an emblem that is connected to these subjects. Over this period the thematic meaning of nonlinearity has changed markedly. At first, in films like The Wrath of Khan, it represented a sort of totalizing vision for the entire universe and the mastery of computation. Soon after, it came to represent the menace of unforeseen events and incalculable risk. In this context it took on a sort of sublime aesthetic quality, inspiring fear, and awe. This is not to say that the reassurance of computational mastery was absent from these films though. Often some sort of diegetic simulation demonstrated that these seemingly random processes and complex systems could in fact be quantified. In the final and most recent phase, nonlinear animation has persevered some of this menace and continues to represent forces beyond understanding, yet characters' relationship to these forces have changed substantially. Here nonlinear uncertainly is a threat not to abhor or to control but to be at peace with, to embrace. In the case of Frozen II it becomes quite literally an animal to be tamed. This is a dramatization of the logic of resilient management and agile development principles profiled in Chaps. 4 and 5 .

The themes in these films represent a broad historical episteme that took shape during this period. This is a way of thinking that has spread to virtually every corner of society. An example from civil hydrodynamics demonstrates this shift in a way that resonated with these films. In the past the conventional way to deal with eroding shoreline was to build bulwarks of seawalls that would stop the incoming waves. This has become a subject of greater importance with anthropogenic climate change. Contemporary research opposes this approach though. Putting up "hard" resistance to the sea does not dissipate the force of waves but instead redirects it, worsening the effects of erosion. Now, specialists in the hydrodynamics of coastal erosion recommend a "soft" approach. Rather than building a wall, for example, they recommend planting mangrove trees to dissipate waves. ${ }^{50}$ This change in approach is no doubt based on empirical data, but it also represents a shift in paradigms and in research tools. Present policy is based on scientific nonlinear simulations, and it exhibits the same changing logic as can be observed in these different eras of films. While 
live-action disaster films like The Perfect Storm or The Day After Tomorrow pit humans against the sea, struggling to escape its menace, animated features like Moana and Frozen II see characters making peace with the sea, and thriving as a result of it.

\section{Notes}

1. N. Katherine Hayles, Chaos Bound: Orderly Disorder in Contemporary Literature and Science (Cornell University Press, 1990).

2. Jean-François Lyotard, The Postmodern Condition: A Report on Knowledge (U of Minnesota Press, 1984), 53-60.

3. Annette Kuhn, Alien Zone (London: Verso, 1990), 7. Andrew Darley, Visual Digital Culture: Surface Play and Spectacle in New Media Genres (Routledge, 2002), 104.

4. Tom Gunning, "The Cinema of Attraction: Early Film, Its Spectator and the Avant-Garde.," in Early Cinema: Space, Frame, Narrative, ed. Thomas Elsaesser (London: British Film Institute, 1990), 57.

5. This is certainly true in North's examples, although he ignores the more quotidian uses of special effects that are not meant to be noticed, like matte painting. Thus his theory should probably be limited to spectacles. Dan North, Performing Illusions: Cinema, Special Effects, and the Virtual Actor (London: Wallflower Press, 2008), 1-5.

6. Jordan Gowanlock, "Promoting Computer Graphics Research: The Tech Demos of SIGGRAPH," in Animation and Advertising, ed. Malcolm Cook and Kirsten Moana Thompson, Palgrave Animation (Palgrave Macmillan, 2019), 276-82.

7. Lisa Purse, Digital Imaging in Popular Cinema (Edinburgh: Edinburgh University Press, 2013), 29.

8. Aylish Wood, "Timespaces in Spectacular Cinema: Crossing the Great Divide of Spectacle versus Narrative," Screen 43, no. 4 (December 1, 2002): 370-86.

9. Whissel, Spectacular Digital Effects, 6-13.

10. Bob Rehak, "The Migration of Forms: Bullet Time as Microgenre," Film Criticism, October 1, 2007, 26-48.

11. Doane, The Emergence of Cinematic Time, 138.

12. Scott Bukatman, Matters of Gravity: Special Effects and Supermen in the 20th Century (Durham: Duke University Press, 2003), 105.

13. Purse, Digital Imaging in Popular Cinema, 22.

14. Michael Rubin, Droidmaker: George Lucas and the Digital Revolution (Gainesville: Triad Pub. Co., 2006).

15. Gowanlock, "Promoting Computer Graphics Research: The Tech Demos of SIGGRAPH," 267-82. 
16. As Chap. 2 explains, nonlinear simulation can be broken into two subtypes: stochastic, which involves the use of random factors, and dynamic, which involves the complexity of multiple co-influencing factors. See pp. 7-21.

17. Benoit B Mandelbrot, Fractals: form, chance, and dimension (San Francisco: W.H. Freeman, 1977).

18. Benoit B Mandelbrot, "How Long Is the Coast of Britain? Statistical SelfSimilarity and Fractional Dimension," Science 156 no. 3775 (1967): 636-638.

19. Heinz-Otto Peitgen and P. H Richter, The Beauty of Fractals: Images of Complex Dynamical Systems (Berlin: Springer-Verlag, 1986).

20. Richard Wright, "Technology Is the People's Friend: Computers, Class and the New Cultural Politics," in Critical Issues in Electronic Media, ed. Simon Penny (Albany: State University of New York Press, 1995), 82.

21. Lucasfilm Computer Graphics Division, Computer Graphics in Star Trek II: The Wrath of Khan," 1982, https://www.youtube.com/watch?v= Qe9qSLYK5q4

22. Manuel DeLanda, Philosophy and Simulation: The Emergence of Synthetic Reason (London: Continuum, 2015), 24.

23. Philip Mirowski, Machine Dreams: Economics Becomes a Cyborg Science (Cambridge: Cambridge Univ. Press, 2006), 12-13.

24. Katherine Hayles, My Mother Was a Computer: Digital Subjects and Literary Texts (Chicago: University of Chicago Press, 2005), 17-27.

25. Warren Sack, The Software Arts, Software Studies (Cambridge, Mass: The MIT Press, 2019), 7.

26. Warren Buckland, "Between Science Fact and Science Fiction: Spielberg's Digital Dinosaurs, Possible Worlds, and the New Aesthetic Realism," Screen 40, no. 2 (July 1, 1999): 184.

27. Peter Galbraith, "Organisational Leadership and Chaos Theory: Let's Be Careful," Journal of Educational Administration 42, no. I (February 1, 2004): 9-28; Helen Gunter, "Jurassic Management: Chaos and Management Development in Educational Institutions," Journal of Educational Administration 33, no. 4 (October 1, 1995): 5-20; David A. Katerndahl, "Lessons from Jurassic Park: Patients as Complex Adaptive Systems," Journal of Evaluation in Clinical Practice 15, no. 4 (August 1, 2009): 755-60.

28. James Gleick, Chaos: Making a New Science (London: The Folio Society, 2015).

29. Doane, The Emergence of Cinematic Time, 2002, 165.

30. Vladimir Igorevič Arnold, Catastrophe Theory (Springer, 1992), 2.

31. Dynamation was noteworthy at the time for its usability because it had a build-in user-oriented scripting language. 
32. AGoogle Ngram search reveals the termwasused little before the book'spublication in 1997, https://books.google.com/ngrams/graph?content=\%22p erfect+storm\%22\&case_insensitive $=$ on \&year_start $=1980 \& y e a r \_e n d=200$ 8 \& corpus $=15$ \&smoothing $=3 \&$ share $=$ \&direct_url $=\mathrm{t} 4 \% 3 \mathrm{~B} \% 2 \mathrm{C} \% 22 \% 20$ perfect $\% 20$ storm $\% 20 \% 22 \% 3 \mathrm{~B} \% 2 \mathrm{Cc} 0 \% 3 \mathrm{~B} \% 2 \mathrm{Cs} 0 \% 3 \mathrm{~B} \% 3 \mathrm{~B} \% 22 \% 20$ perfect $\% 20$ storm $\% 20 \% 22 \% 3 \mathrm{~B} \% 2 \mathrm{Cc} 0 \% 3 \mathrm{~B} \% 3 \mathrm{~B} \% 22 \% 20$ Perfect $\% 20$ Storm $\% 20$ \%22\%3B\%2Cc0. "Perfect Storm - Definition of Perfect Storm in English | Oxford Dictionaries," Oxford Dictionaries I English, accessed March 4, 2017, https://en.oxforddictionaries.com/definition/perfect_storm

33. For one of many examples see: Manav Tanneeru, "How a 'perfect storm' led to the economic crisis," CNN, 29 January 2009, http://articles.cnn. com/2009-01-29/us/economic.crisis.explainer_1_housing-bubblehousing-market-wall-street?_s=PM:US (accessed 12 January 2015).

34. M. Pauline Baker and Colleen Bushell, "After the Storm: Considerations for Information Visualization," National Centre Supercomputing Applications University of Illinois, http://vis.iu.edu/Publications/Storm. pdf (accessed 12 January 2015), 1.

35. John Vince and Rae Earnshaw, Visualization and Modelling (Morgan Kaufman, 1997), 2.

36. Sean Cubitt, “Le Réel, C'est Impossible: The Sublime Time of Special Effects," Screen 40, no. 2 (1999): 128.

37. Bukatman, Matters of Gravity, 81 .

38. Bukatman, Matters of Gravity, 160.

39. The idea for An Inconvenient Truth was reportedly formed at the world premier for The Day After Tomorrow. Andrew C. Revkin, "An Inconvenient Truth - Al Gore - Movies," The New York Times, May 22, 2006, http:// www.nytimes.com/2006/05/22/movies/22gore.html

40. Interestingly, The Day After was the next film project of director Nicholas Meyer after Star Trek II: The Wrath of Khan.

41. See Chap. 3, pp. 21-22.

42. Roland Emmerich directed both The Day After Tomorrow and Independence Day, and he has a signature style of spectacular destruction.

43. James E. Overland et al., "Nonlinear Response of Mid-Latitude Weather to the Changing Arctic," Nature Climate Change 6, no. 11 (November 2016): 992-99.

44. Paul N. Edwards, A Vast Machine: Computer Models, Climate Data, and the Politics of Global Warming (Cambridge, Mass.: The MIT Press, 2013), xiiv.

45. Mark J. P. Wolf, Abstracting Realty (U P of America, 2000), 262.

46. Wolf, Abstracting Realty, 269.

47. Catmull and Wallace, Creativity, Inc., 2014, 139.

48. Catmull, "How Pixar Fosters Collective Creativity," September 1, 2008. 
49. Lauren Dundes argues that Nøkk has become Elsa's de facto companion in the series, sidestepping the possibility of her either being a queer character or having a straight relationship where she retainers her power. Lauren Dundes, "Elsa as Horse Whisperer in Disney's Frozen 2: Opportunity 'Nokk's to Quash Gender Stereotypes," Social Sciences 9 (May 20, 2020): 86 .

50. Joseph Bennington-Castro, "Walls Won't Save Our Cities from Rising Seas. Here's What Will," NBC News, accessed November 18, 2020, https://www.nbcnews.com/mach/science/walls-won-t-save-our-cities-risingseas-here-s-ncna786811

Open Access This chapter is licensed under the terms of the Creative Commons Attribution 4.0 International License (http://creativecommons.org/licenses/ by $/ 4.0 /$ ), which permits use, sharing, adaptation, distribution and reproduction in any medium or format, as long as you give appropriate credit to the original author(s) and the source, provide a link to the Creative Commons license and indicate if changes were made.

The images or other third party material in this chapter are included in the chapter's Creative Commons licence, unless indicated otherwise in a credit line to the material. If material is not included in the chapter's Creative Commons licence and your intended use is not permitted by statutory regulation or exceeds the permitted use, you will need to obtain permission directly from the copyright holder. 